\title{
¿COMPLICIDAD O INGENUIDAD? REFLEXIÓN ANTROPOLÓGICA SOBRE LA DUALIDAD GUERRA-PAZ
}

\author{
COMPLICITY OR NAIVETY? ANTHROPOLOGICAL REFLECTION ON \\ THE DUALITY WAR-PEACE
}

\author{
Gloria Luque Moya \\ Universidad de Málaga (España)
}

Recibido: 20-05-2012

Aceptado: 26-06-2012

Resumen: Este texto parte de la tesis de Eric Wolf, la cual presenta a la humanidad como ese conjunto de procesos múltiples interconectados. Esto es, los seres humanos construyen su historia día a día, mediante ese proceso continuo que entreteje y deshilacha redes y vínculos. A partir de ahí, el texto irá destacando esos vínculos y conexiones, en referencia a la temática guerra-paz, a través de un proceso clave en la historia de la antropología, la colonización africana. De este modo, tras presentar la reflexión posterior en torno al hecho de la colonización, así como la reflexión de la misma por parte de los propios antropólogos de la época colonial, el texto trata de mostrar como las culturas no son entes separados y aislados, y como es necesario ampliar nuestro horizonte si queremos abordar una temática tan controvertida y relevante como es la guerra y la paz.

Palabras-clave: colonización, indirect rule, funcionalismo, cambio cultural.

\begin{abstract}
This paper is based in Eric Wolf's thesis, which presents mankind as a set of multiple interconnected processes. That is, human beings build their history every day, through a continuous process with different links and connections. This text presents those connections through an important moment in the history of anthropology, colonisation. Thus, after presenting the reflection about colonisation by contemporary anthropologies, and also by anthropologies who live in colonial period, the paper seeks to show how culures are not separated and isolated entities, and how it is necessary to broaden our minds if we want to tackle a controversial and important issue such as war and peace.

Key-words: colonisation, indirect rule, functionalism, cultural change.
\end{abstract}


En un contexto en el que la comunicación y la información traspasan fronteras y abogan por un ámbito internacional, un mundo en el que hemos erigido organizaciones internacionales ${ }^{1}$ con el objetivo de regular y garantizar aquello que consideramos inviolable, llámense derechos fundamentales, condiciones justas y de respeto o de cualquier otra manera, la consideración de las nociones guerra y paz nos plantean un gran reto. Las cifras, las cuales hablan de más de 20 conflictos armados a día de hoy, algunos de ellos vigentes desde hace ya más de treinta años, resuenan tan ferozmente que la reflexión en torno a ellos resulta ineludible. Si bien, esta comunicación no pretende atender a algunos de estos conflictos con detenimiento, y ello se debe y ello se debe a que el punto de partida que marca esta propuesta se cimienta sobre la tesis de Eric Wolf de que la humanidad constituye un conjunto de procesos múltiples interconectados ${ }^{2}$. Ahora bien ¿qué queremos decir con esto de procesos múltiples interconectados? El planteamiento que se delinea a partir de lo expuesto por Wolf es que reflexionar sobre la guerra o la paz, sobre un conflicto armado concreto o en general, resulta superficial si no tenemos en cuenta que los seres humanos construyen cada día su propia historia, en un proceso continuo en el que se entretejen y deshilachan redes y vínculos constantemente.

La propuesta de estas páginas, por tanto, se centra en recuperar la importancia de aquellas conexiones o vínculos que hemos perdido al regir nuestros estudios en base a nociones que lo limitan y lo hacen manejable, y que, sin embargo, conllevan la pérdida de las relaciones interdisciplinares inmersas en estos procesos. Eric Wolf dedicará la primera parte de su libro Europa y la gente sin historia a relatar esas conexiones enfatizando en el hecho que no es constitutivo del ser humano ese rígido patrón que tiende a separar en nociones duales del tipo occidente-oriente. Igualmente importante, y si cabe de manera más consagrada, se presentan las reflexiones de Edward Said en su libro Orientalismo en el cual va a reclamar el tratamiento de Asia sin su opuesto Europa y/u Occidente; para ello se desvinculará de todas aquellas aproximaciones que compartimentalizan y establecen distinciones que rebajan y degradan todo aquello que no sea proveniente de Occidente. Es decir, va a rechazar todos aquellos estudios basados en la aplicación del método científico para el estudio de otras culturas, los cuales no sólo reducen los diferentes pueblos a un objeto de dominio, sino que también silencian su voz. Su dura crítica hiere directamente al antropólogo, ya que presenta su actividad cognoscitiva como aquella que niega la autonomía y autoridad a las culturas, como aquella que somete a culturas, en principio ya liberadas.

[1] Cf. La carta de las Naciones Unidas, especialmente el preámbulo de la misma donde se expresa la declaración de intenciones de dicho texto y donde se fija la finalidad de la organización.

[2] Wolf, Eric. Europa y la gente sin historia. México D.F.:Fondo de Cultura Económica, 1982, p. 15 .

THÉMATA. Revista de Filosofía, Nº48 julio-diciembre (2013) pp.: 65-74

doi: 10.12795/themata.2013.i48.05 
En este sentido, aunque esta propuesta podría resultar pretenciosa por tan difícil tema en tan breve escrito, resulta imperioso realizar una aproximación a esta tesis por la relevancia que ella tiene en nuestros días. Para ello, sirviéndome de uno de los mayores hitos dentro de la historia de la antropolo $\neg$ gía, la colonización, presentaré dos caras de una misma moneda; por un lado, expondré la reflexión posterior en torno al hecho de la colonización y como los antropólogos no quisieron cuestionar parte de esa realidad que configuraba a esa población o si lo hicieron fue de manera superficial; por otro lado, expondré esto mismo a través de la voz de antropólogos de la época colonial, mediante una obra clave de la antropología: African Political Systems ${ }^{3}$.

\section{El papel del antropologo en la colonización.}

El estudio de la colonización podría tratarse desde los más diversos aspectos, lugares, culturas o épocas. Sin embargo, lejos de retratar realidades, a lo largo de este punto consideraré aspectos tan importantes como las interpretaciones establecidas, el papel jugado por la antropología y el nacimiento de la profesión del antropólogo durante el periodo de colonización africana.

La ocupación armada del continente africano se inicio con la Conferencia de Berlín, reunida bajo un sinfín de pretextos humanitarios y antiesclavistas que querían dar fin a la trata de negros y comprometerse con el desarrollo de la zona, y finalizará en torno a 1904. Esto se tradujo en un territorio fragmentado en parcelas rígidas de pertenencia europea, explotados como objetos a partir de los cuales poder ampliar sus fuentes de riqueza y obtener los máximos beneficios. Ahora bien, la manera de proceder por parte de los estados europeos siguió dos modelos administrativos diferenciados: el conocido como británico (que emplearon Reino Unido y Alemania) y el denominado francés (que emplearon Francia, Portugal, Bélgica e Italia) ${ }^{4}$. Aquí nos ocuparemos exclusivamente del británico debido a las consecuencias que éste conlleva en el mundo de la antropología. El modelo británico, también conocido como indirect rule, no quiso instaurar las políticas propias de su país, ni siquiera implanto el ingles como idioma oficial, tal y como si que sucedió en las colonias francesas, sino que mantuvieron las jerarquías de poder existentes y le otorgaron a esos africanos la labor de recaudar el tributo y reclutar la fuerza de trabajo. Es decir, manteniendo las antiguas estructuras de poder el gobierno británico les atribuía un papel de mediador a los que ostentaban poder y respeto en esa tradición cultural.

[3] Fortes, Meyer, Evans-Pritchard, E.E. (eds) African Political Systems. London: Oxford Univesity Press, 1950 (5º edición).

[4] Para una aproximación más detallada a los dos tipos de regímenes coloniales cf. Fernandez Moreno, Nuria (ed). Antropología y colonialismo en África subsahariana. Madrid: Editorial Ramón Areces, 2009.

THÉMATA. Revista de Filosofía, ${ }^{\circ} 48$ julio-diciembre (2013) pp.: 65-74 doi: 10.12795/themata.2013.i48.05 
Esta realidad va a propiciar la profesionalización del antropólogo, que ya no sólo estudia las culturas desde su despacho, sino que se traslada al terreno para analizarlas y estudiarlas. Para dicha labor se sirvieron de las facilidades financieras y materiales que la administración colonial les proporcionaba por su necesidad de saber más sobre las poblaciones conquistadas. De hecho, es en este periodo cuando se publican obras cumbres de la antropología, tales como The Nuer de Evans-Pritchard The Dynamics of Clanship Among the Tallensi por Meyer Fortes, y algunos de los volúmenes editados más conocidos como fueron Sistemas africanos de parentesco y matrimonio y Sistemas políticos africanos. Si bien, esto no debe hacernos pensar que no existieron fricciones y situaciones tensas con las administraciones coloniales; el antropólogo de campo quiso ocupar una posición favorable para la comprensión de aquellas culturas, por ello tratará de mantenerse independiente respecto al administrador, denominado "profano". Sin embargo, el carácter más problemático que plantea la antropología en este contexto, y paso a detenerme en el mismo, es la posición que adopta ante la indirect rule. Los antropólogos de este periodo, pertenecientes en su mayoría a la corriente funcionalista, no sólo no criticaron la colonización, sino que apoyaron la indirect rule sin ningún tipo de reparo. El propio Malinowski defendía la indirect rule por la viabilidad de su proyecto, el cual se presentaba acompasado e incluso pausado, frente a la colosal, apresurada e impracticable labor de la direct rule ${ }^{5}$. Sólo a través de ese control indirecto Malinowski ve posible el desarrollo de la vida económica, la administración de justicia por nativo para nativos, el nacimiento de una moral y educación en líneas indígenas y el desarrollo de un verdadero arte, cultura y religión africana ${ }^{6}$.

En este sentido, ¿se puede decir que no atisbaron una auténtica ocupación del territorio con el único objetivo de obtener el máximo beneficio con su explotación? Lecler ${ }^{7}$ ha expuesto hábilmente dos de los aspectos por los que los antropólogos no hicieron una reflexión crítica sobre la propia colonización. El primero de ellos será el neutro concepto funcionalista de cambio cultural que presenta la colonización como mera aculturación. Los funcionalistas se limitaran a describir la situación sin atender a los motivos del colonialismo y las consecuencias del mismo. Ellos ni legitiman, pero tampoco condenan, no

[5] "The real difference between 'direct rule' and indirect or dependent rule' consists in the fact that direct rule assumes that yo can create at one go and entirely new order, that you can transform Africans into semi-civilized pseudo-European citizens within a few years. Indirect rule, on the other hand, recognizes that no such magical rapid transformation can take place, that in reality all social development is very slow, and that it is infinitely preferable to achieve it by a slow and gradual change coming from within" [Malinowski. "Practical Anthropology", África 2:1 (1929), p. 23].

[6] Ibid, p. 24.

[7] Leclerc, G. "Antropología y colonialismo" en Antropología y colonialismo en África subsahariana. Madrid: Editorial Ramón Areces, 2009, pp. 109-144.

THÉMATA. Revista de Filosofía, Nº 48 julio-diciembre (2013) pp.: 65-74 doi: 10.12795/themata.2013.i48.05 
juzgan el sistema porque se trata de una forma diferente de cambio, de hecho Malinowski lo califica como un give and take $e^{8}$. El segundo de ellos será el lugar que pasará a ocupar la antropología por esa necesidad por parte del régimen colonial de conocer las organizaciones locales para poderlas utilizar. Su nacimiento no se erige sobre ese lecho de autonomía e independencia que el antropólogo se quería atribuir. Si seguimos avanzando en la lectura del artículo de Malinowski ${ }^{9}$ podemos percibir la importancia que le concede a la antropología en cuanto que será la que proporcione la información de manera más correcta.

Igualmente Evans-Pritchard se sitúa en la misma línea, e incluso da un paso más afirmando que es importante que los antropólogos actúen como consejeros o asesores de la administración siendo un pleno miembro de la misma ${ }^{10}$. Para Evans-Pritchard, hay que conocer los problemas burocráticos, y para ello, hay que pertenecer a la misma para poder tener acceso a los documentos, datos e informes, aunque su tratamiento sea antropológico y no administrativo. Así pues, la posición que ocuparon los antropólogos se enmarcó dentro de esos juegos de poder coloniales en los que se hallaban inmersos, y aunque los antropólogos a través de sus estudios intentaron dar a conocer la cultura y desarrollo de estos pueblos para una mejor convivencia, no es menos cierto que es debido a esta situación de dominio y explotación desde la que la antropología da un giro más práctico y experimenta su gran desarrollo como disciplina de conocimiento $^{11}$.

\section{Aproximación a la relación antropología-colonización desde el texto etnográfico.}

Llegados a este punto, resulta ineludible relacionar estas reflexiones con alguna obra etnográfica de la época, y en este sentido, el compendio de African Political Systems se presta como uno de los escritos más relevantes e interesantes a este respecto. Dicha obra conforma un compendio de textos elaborados por antropólogos de diferente procedencia que exponen a lo largo

[8] La formula del give and take viene a mantener que ambas culturas (tanto la conquistada como la conquistadora) dan y reciben nuevas pautas culturales en esa interacción, sin atender las relaciones de dominio o violencia generadas y determinantes par ala configuración de ese intercambio.

[9] "That type of study (studies of the political organization of native tribes) is really a piece of anthropological fieldwork for which the trained anthropologist has developed devices and methods which allow him to observe, to write down his observations and to formulate them much more rapidly than a layman can do, exactly as the trained geologist sees details and reads on the face of the earth important geological principles completely hidden from the most intelligent but untrained observer" [Malinowski, op. Cit. 1929, p. 25].

[10] "It is important that the anthropologist who acts as adviser, or consultant, to an administration should be a full member of it". [Evans-Pritchard, E.E. "Applied Anthorpology" en Africa, 16: 2 (1948), p. 97.

[11] Cf. Wilson Godfrey. "Anthropology as a Public Service”, África, 13: 1 (1940), pp. 43-61.

THÉMATA. Revista de Filosofía, $\mathrm{N}^{\circ} 48$ julio-diciembre (2013) pp.: 65-74 doi: 10.12795/themata.2013.i48.05 
de esas páginas las observaciones recogidas durante sus trabajos etnográficos. La extensión de estos documentos hace inabarcable la consideración completa del mismo aquí, por ello en estas páginas me centraré especialmente en la "Introducción"12 escrita por Fortes y Evans-Pritchard. Esto no debe extrañar, ya que el rico contenido de la misma requiere un estudio detenido que trate los aspectos fundamentales allí desarrollados como son: el objetivo que los reúne; su postura ante la filosofía, y más concretamente la filosofía política; las correlaciones e influencias de diferentes aspectos que los distinguen; y el tratamiento de los cambios que se han llevado a cabo desde la conquista y dominación europea.

Centrándonos en el primero de dichos aspectos, la motivación y objetivos para elaborar tal libro lo sitúan en la importancia de un libro de consulta que fuera útil para antropólogos, en el que fueran representadas los tipos más comunes de sistemas políticos africanos. Empleando los métodos más modernos de trabajo de campo describen los principios básicos de organización política de ocho sociedades, tomándolas como muestras representativas de la sociedad africana. Así con este estudio comparado pretendían proporcionar bases etnográficas desde las cuales extraer conclusiones de tipo general y teórico. Ellos engloban los sistemas recogidos en su libro dentro de dos categorías fundamentales el Grupo A, compuesto por sociedades en las que existe autoridad centralizada, administraciones e instituciones jurídicas propias; en contraposición al Grupo B que carece de todo ello; esto es, sociedades con estado primitivo, como los zulu o bemba y sociedades sin estado como los tallensi o los nuer. Aunque quizás una de las características más destacadas que diferencia ambos grupos es el papel que juega el parentesco en su organización política, ya que para el grupo B la organización administrativa vendrá establecida por el sistema de linajes, mientras que para el grupo A será la organización administrativa la que organice de manera -independiente- las relaciones políticas según los segmentos territoriales.

Así pues, este compendio de ensayos trata de proporcionar un libro de consulta para todos, ya sean antropólogos especializados o personal de la administración que quiera acceder al conocimiento de estas culturas. En este sentido, los autores se limitan al ámbito descriptivo, de hecho ellos mismos afirman no haber recurrido a teorías filosóficas o principios de la filosofía política para no generar controversias y porque más que ayudar a comprender las sociedades allí presentadas las enturbian. Ahora bien, ¿cuál es el motivo por el que las teorías filosóficas no ayudaban al antropólogo, sino que todo lo contrario lo sumergía en un terreno fangoso de equivocaciones? Fortes y Evans-Pritchard apuntan como los filósofos políticos se habían ocupado sólo

[12] Para el análisis de la "Introducción" utilizaré la traducción al castellano de la misma recogido en Llobera, J.R. (ed) Antropología política. Barcelona: Anagrama, 1979.

THÉMATA. Revista de Filosofía, Nº 48 julio-diciembre (2013) pp.: 65-74 doi: 10.12795/themata.2013.i48.05 
del deber ser y cuando habían tratado de comprender las instituciones existentes procedieron aplicando principios teóricos o tesis que trataban de descubrir unos orígenes o inicios que no se correspondían con la realidad. Ahora bien, ésto no debe cegarnos porque podemos vislumbrar problemas similares en los antropólogos aquí tratados. Fortes y Evans-Pritchard, aunque advierten que dichas muestras representativas no se pueden extender a todos los grupos de su alrededor, abanderan su trabajo desde una posición científica y objetiva que no es real. Como bien se ha señalado posteriormente, el antropólogo no puede deslindarse de sus raíces culturales, de su forma de interpretar e interactuar la realidad, y al realizar estos trabajos etnográficos los autores los elaboraron no sólo desde sus patrones culturales, sino con el aval y apoyo de los mismos, por ese proceso de colonización.

En esta misma línea, cabe sugerir algunos puntos significativos respecto a las correlaciones e influencias. Fortes y Evans-Pritchard hábilmente destacan la relación de factores demográficos, condiciones ecológicas, modos de subsistencia y organización política. De hecho, siguiendo las dos categorías distinguidas apuntan como la unidad política en sociedades con organización estatal (grupo A) es mayor que las sociedades sin estado (Grupo B). Del mismo modo, las condiciones del medio y los distintos modelos económicos determinaran los valores dominantes en estos pueblos, así como su organización política y social. Sin embargo, aunque su estrategia y observaciones son sumamente importantes ya no sólo por lo que recogen y contienen, sino también por la hábil perspectiva comparativa, dichos autores también realizan valoraciones desde su propia cultura de procedencia. Calificativos tales como primitivo o rudimentario muestran la debilidad cultural del antropólogo al poner en contacto sus patrones culturales con los de otros pueblos. El modo económico de subsistencia, tal y como ellos lo definen, no actúa independientemente de esas estructuras de poder o status, de hecho no cabe denominarlos modelos primitivos, sino que por esa misma importancia otorgada a la relación con el medio, con la demografía, habría que hablar, como la antropología económica lo hace hoy en día, de distintos modelos económicos con puntos de énfasis claramente diferenciados. La distinción entre trabajo productivo y tiempo de ocio o la acumulación de riquezas en forma de capital, entre otros, no son más que nociones relativamente recientes de un modelo económico que trata de expandirse al mundo como el más elaborado y complejo, pero en realidad al hacerlo escinde a los pueblos del contexto en el que nacieron y en el que se desarrollan.

Quizás en estos términos sea aún más destacado el tratamiento que hacen de los cambios producidos. Ya en la primera página de dicha introducción señala que, aunque son conscientes de que esta interacción dominante modifica los sistemas, no se centran en ella porque lo que les interesa son los problemas antropológicos, no los problemas administrativos. Y si bien es cierto que tratan los cambios producidos en los sistemas políticos a partir de esa con-

THÉMATA. Revista de Filosofía, No 48 julio-diciembre (2013) pp.: 65-74 doi: 10.12795/themata.2013.i48.05 
quista, piénsese en la transformación de sociedades como los tallensi y nuer a estados como el de los zulúes ${ }^{13}$, su aproximación científica u objetiva les limita no sólo a la hora de establecer valoraciones respeto a esa conquista, como lo haría el filósofo según estos autores, sino que también circunscribe su exposición a aspectos concretos de un grupo en un continuo proceso constitutivo. De esta manera, al analizar las diferentes respuestas de los pueblos africanos al dominio europeo sin reflexionar crítica y abiertamente sobre el mismo, por esa "objetividad" que pretenden conservar por encima de todas las cosas, caen en una falacia similar a la que atribuían a los filósofos: su descripción etnográfica se manifiesta como lo que debe ser para el antropólogo. Al proceder de este modo se volvían cómplices, por tanto, de una conquista que no sólo vulneraba y constreñía los sistemas que querían estudiar, sino que imponía una serie de cambios estructurales que quedaban fuera de la descripción y el análisis por ser denominados meramente administrativos.

\section{Concluyendo lo inconcluso o de la humanidad en su continuo constituir.}

Antes de finalizar este escrito cabe lanzar una cuestión ¿qué aporta una reflexión como ésta a la luz de nuestros días? Como ya se anunció en las primeras páginas de este escrito el punto de partida era la tesis de Eric Wolf según la cual la humanidad esta en un continuo construir, por ello, se afirmaba que resultaba paradójico, cuando no cuestionable, centrar la reflexión filosófica y antropológica en torno a puntos o aspectos aislados de ese constante proceso, y la dualidad guerra y paz puede desviarnos de aspectos y vínculos claves de dicho quehacer. No se puede tratar el estudio de dichas culturas ni de ninguna otra como entes separados; como Said ha señalado, el acercamiento a otra cultura no significa la aproximación a un todo fijo e inmutable reconocible por fotogramas, y el tratamiento de la colonización tal y como ha sido expuesto es buena prueba de ello. Entonces ¿cómo podemos proceder? ¿qué podemos extraer de todo esto?

El ímpetu que mueve estas páginas no es otro más que el de ampliar nuestro horizonte. La literatura antropológica, y especialmente la filosófica, ha usado nociones duales del tipo guerra-paz para exponer imágenes estáticas de los flujos temporales. Ello facilita su descripción e incluso podría hacernos creer que mediante esta manera de proceder alcanzamos un conocimiento -objetivo- o -científico-. Sin embargo, esto no sólo nos aleja de la realidad, sino que además nos ciega ante el devenir de la vida. En estas páginas he aludido a la colonización, y quizás convenga concluir aludiendo a un ejemplo africano de conflicto armado que especifique la necesidad de esta apertura: el genocidio

\footnotetext{
[13] Ibid., p. 92.
}

THÉMATA. Revista de Filosofía, Nº48 julio-diciembre (2013) pp.: 65-74 doi: 10.12795/themata.2013.i48.05 
de los tutsis llevado a cabo en Ruanda por la población Hutu. Los tutsi y los hutu no pueden considerarse pueblos o culturas diferentes, sino que más bien se trata de diferentes castas con sus propias ocupaciones (unos son pastores y los otros agricultores), jerarquías y relaciones endógamas.

A principios del siglo XX los tutsi dominaban a los hutus, a pesar de que los primeros sólo componían el 10\% de la población frente a los segundos que conformaban un 50\%. J. Maquet ${ }^{14}$ entretejió varios de los factores que hacían posible mantener dicha dominación: en primer lugar, la configuración del país con una cadena montañosa que separaba las cuencas del Congo, dificultando la comunicación para el gobierno centralizado; en segundo lugar, las inclemencias de suelo, precipitaciones y método de cultivo impidieron la producción de excedente necesaria para el desarrollo de tal tipo de gobierno; en tercer lugar y quizás el más destacable, aunque la cultura de los tutsi no era diferente a la de los hutus estos supieron mantener una identidad de casta y el dogma de la superioridad innata como elemento fundamental para su dominio; $\mathrm{y}$, si bien los tutsi patrocinaron este tipo de ideal, también desarrollaron otras circunstancias de solidaridad para equilibrar esa distinción. Es más uno de los factores integradores de mayor arraigo ideológico fue la institución monárquica por la cual el rey de los tutsi de origen divino era el rey de todo el territorio. Los vínculos y elementos que configuraban esta sociedad eran tan complejos que los colonos belgas, en función de sus intereses, consideraron a los tutsi una raza superior, afianzándolo en 1934 con la introducción de un carné étnico que otorgaba a los tutsis mayor nivel social y los dotaba de grandes privilegios; quedando institucionalizado así esta relación de dominio.

Las nuevas concepciones, el apoyo colonial para el monopolio tutsi del poder social, político y económico y las nuevas relaciones que ello conllevaron hacen sumamente complejo el proceso por el cual más de un $80 \%$ de los tutsi ruandeses fueron exterminados en 1994. De hecho se presenta aún más difícil si tenemos en cuenta la procedencia de la financiación hutu para dicho plan, en su mayoría procedente del Banco Mundial y el Fondo Monetario Internacional; o las consecuencias internacionales que ello supuso, quizás la más relevante sea la creación de una Corte Penal Internacional permanente que persiguiera y condenara los crímenes más graves (genocidio, crímenes de lesa humanidad y crímenes de guerra) cometidos por individuos.

A modo de conclusión, se puede afirmar que la humanidad es un proceso en continua construcción e interacción; por ello, el genocidio de Ruanda no habla de una guerra tribal o étnica, sino de fases de violencia y conflicto generada por esa trama de relaciones y conexiones que confeccionan los diferentes

[14] Para la exposición de los elementos determinantes desencadenantes de este conflicto seguiré el artículo y los puntos presentados por J. Maquet en "El problema de dominación Tutsi" expuesto en el Internacional Congress of Anthropological and Ethnological Sciences en Viena 1-8 de septiembre, 1952. [Llobera, J.R. op. cit., pp. 317-322].

THÉMATA. Revista de Filosofía, $\mathrm{N}^{\circ} 48$ julio-diciembre (2013) pp.: 65-74 doi: 10.12795/themata.2013.i48.05 
pueblos. En este sentido, se presenta necesario el desarrollo de una reflexión crítica desde el ámbito de la antropología filosófica que recoja estas tesis y amplíe su campo de estudio atendiendo a los eventos olvidados que acontecen en nuestros días, esto es, no padecer de ingenuidad, pero tampoco hacernos cómplices:

"Mea culpa. No tanto por haber pecado de corto de vista, sino más bien por no haber presentido lo que allí se gestaba y que iba a dislocar lo que parecía permanente. ¿No había visto nada, de verdad? ¿Ceguera de quien se beneficia de las ventajas de una nación y de una situación momentánemanente privilegiada? Me parece también que en mi fuero interior debía oponer una resistencia a la idea de la completa transformación de estos países, que se me antojaban necesariamente forzados, para llegar al cambio, a pasar por el Occidente, por sus ciencias, sus métodos, sus ideologías, sus organizaciones sociales sistemáticas." 15

[15] Michaux, Henri. Un bárbaro en Asia, tr. Jorge Luis Borges. Barcelona: Tusquets, 2001, p. 16.

THÉMATA. Revista de Filosofía, Nº48 julio-diciembre (2013) pp.: 65-74

doi: 10.12795/themata.2013.i48.05 